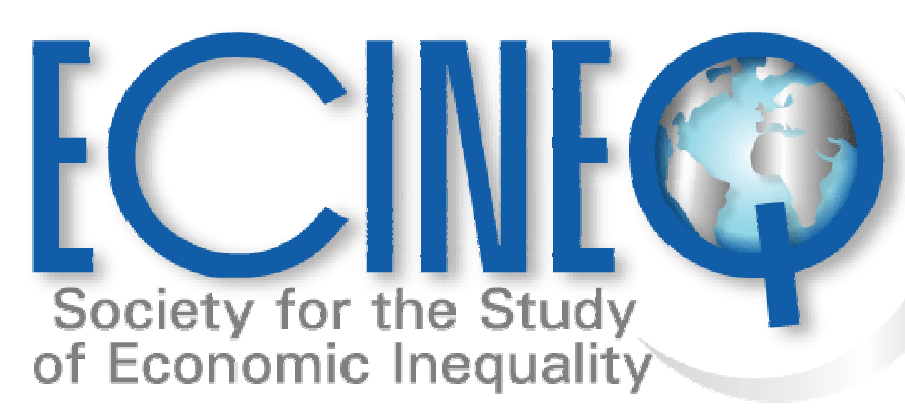

\author{
Working Paper Series
}

Skill Premia and Intergenerational Skill

Transmission: The French Case

B. Ben Halima

N. Chusseau

J. Hellier 


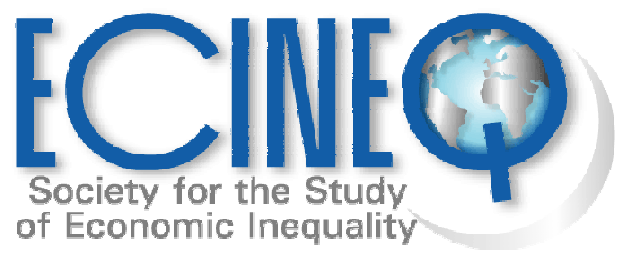

ECINEQ $2013-285$

January 2013

www.ecineq.org

\title{
Skill Premia and Intergenerational Skill Transmission: The French Case*
}

\author{
B. Ben Halima \\ N. Chusseau \\ EQUIPPE, Univ. of Lille 1 and MESHS \\ J. Hellier \\ LEMNA, University of Nantes
}

\begin{abstract}
In the case of France, we analyse the changes (i) in the skill premium linked to each level of education and (ii) in the impact of parents' skill and income upon the educational attainment of their children. To this end, we build a theoretical model which is subsequently estimated. Our calculations firstly reveal (i) a critical decline in the skill premium of the Baccalaureate in relation to the lowest skill level, and (ii) an increase in the skill premia of higher education in relation to the Baccalaureate, which however is not large enough to avoid the decrease in all the skill premia relative to the lowest skill. Secondly, we find (i) a significant increase in the impact of the family backgrounds upon the individuals' education from 1993 to 2003 which essentially derives from a higher impact of parental income upon the educational attainment, and (ii) an increase in the impact of public expenditure upon education. Consequently, if inequality has decreased among the employed population, the slowdown in intergenerational mobility could reverse this tendency in the longer term. This may however be offset by higher public educational expenditure.
\end{abstract}

Keywords: Family backgrounds, intergenerational mobility, return to education, skill premium.

JEL Classification: I2, J24, J31.

\footnotetext{
* We wish to thank the French Research National Agency (ANR) for its financial support. In addition, we thank Frédéric Séraphin for his contribution to an early version of this paper. Contacts: Joël Hellier: joel.hellier@wanadoo.fr
} 


\section{Introduction}

The aim of this article is twofold. It firstly determines the variations in the skill premia linked to each level of education in France over the period 1977-2003. From this first result, we analyse the intergenerational skill transmission for the individuals surveyed in 1993 and 2003.

Since the seminal work of Mincer (1974), a large body of empirical literature has analysed the impact of education upon wages. These works typically diagnose a large and significant impact (see the reviews of Psacharopoulos, 1985 and 1994; Cohn and Addison, 1994; Card, 1999; Black and Devereux, 2011). In line with Mincer's equation, most empirical studies have measured the education level by the schooling years above a lower limit of 6 or 7 years (Psacharopoulos and Patrinos, 2004). In their review of the empirical works on France, Hanchane and Moullet (2000) present eight studies, all of them measuring human capital by the number of schooling years. Nevertheless, this measure suffers several limitations. In particular, it gives the same weight to all the schooling years regardless of the educational level. Several studies have found decreasing returns to the schooling years (Psacharopoulos, 1994; Wössmann, 2003). In their analyses of the French case, Jarousse and Mingat (1986) and Goux and Maurin (1994) have improved the measure based on schooling years by accounting for repeated years and by distinguishing the certified from the non certified years. Introducing qualitative variables, Jarousse and Mingat (1986) also find that, compared to the average return to the related schooling years, the University 'Deuxième Cycle' (final two Degree years) shows a wage deficit of 9\% whereas the 'Grandes Ecoles' (Post Graduate Schools) Degree benefits from a wage surplus of $30 \%$. These results suggest that the wage value of one schooling year can critically differ depending on the stage and the type of study considered.

Since Becker and Tomes (1976, 1979, 1986), the family background has been considered as a key determinant of children's education and income (Piketty, 2000; Chusseau and Hellier, 2012). A sizeable impact indicates a low intergenerational mobility. The influence of parents on their children's human capital runs through several channels. Firstly, intra-family human capital externalities and transfers impact upon both the children's human capital and their capacity to learn. In this respect, a number of empirical works have underlined the influence of parental characteristics upon children's performance at school (Acemoglu and Pischke, 2001, for the US; Ermisch and Francesconi, 2001, for the UK; Lauer, 2003, for Germany and France; Checchi et al., 2008, and Brunello and Checchi, 2005, for Italy, Liu et al., 2000 and 2006, for Taiwan). A second channel of influence comes from the impact of 
parents' income on the funding of their children's education. Highly skilled parents have higher incomes and can thereby invest more in their offspring's education, resulting in higher skill and incomes of their children (Solon, 2004). Family funding is essential when credit market imperfections prevent youngsters from borrowing for their education (Becker and Tomes, 1979; Mulligan, 1997; Han and Mulligan, 2001; Grawe and Mulligan, 2002; Grawe, 2004). In addition, children with educated parents are more and better informed (Entwistle and Alexander, 1992). Finally, the literature has pointed to the genetically transmitted differences in ability (Miller et al., 1995; Ashenfelter and Krueger, 1994; Rouse, 1999; Bowles and Gintis, 2001, 2002).

The impact of parents' position upon children's attainment has typically been estimated by intergenerational elasticities of earnings and/or education.

An abundant empirical literature has analysed the impact of parent's income upon the child's income through intergenerational earnings elasticities ${ }^{1}$. Intergenerational income elasticities critically differ across countries, the lowest values (less than 0.3) being found in Nordic countries (Björklund and Jäntti, 1997; Österberg, 2000; Jänti et al., 2006) and the highest (between 0.4 and 0.6) in the US (Solon, 1992; Jänti et al., 2006; Mazumder, 2005), the UK and France being in-between (Nicoletti and Ermisch, 2007 and Blanden et al., 2004 for the UK; Lefranc and Trannoy, 2005 for France).

Intergenerational mobility has also been measured by the influence of parents' human capital on their children's human capital (education). In these works, human capital is typically measured by the number of schooling years, and OLS are used to estimate intergenerational human capital elasticity. For the US, Mulligan (1997) finds an intergenerational coefficient of 0.32 between father and son, and 0.33 between father and child. For the UK, Dearden et al. (1997) find 0.424 for the father-son coefficient and 0.415 for the father-daughter coefficient. Comparing the US and Germany, Couch and Dunn (1997) find a father-son intergenerational coefficient of 0.42 in the US and 0.24 in Germany. This reveals higher persistence in the former. Using the French database Formation Qualification Professionnelle (FQP) in 1993, Fabre and Moullet (2004) find an intergenerational coefficient of education of 0.31 between father and son and a mother-son coefficient of 0.29 . By using the number of schooling years to measure human capital, these empirical works are exposed to the already mentioned critique of allocating the same weight to qualitatively different schooling years.

\footnotetext{
${ }^{1}$ Solon (2002), Grawe (2004), Jäntti et al. (2006), Mazumder (2005), Nicoletti and Ermisch (2007), Björklund and Jäntti (2009), Blanden (2009), Corak (2006), Black and Devereux (2011) etc.
} 
In this article, we firstly develop a theoretical model in which individuals choose their skill level by maximising the return to education, with the different stages/cycles of education providing uneven income gains and the educational attainment depending on the parents' skill and income. We subsequently estimate a slightly modified empirical version of the model on the French database FQP, (i) to quantify the return (skill premium) to each level of the French educational system, and (ii) to measure the impact of the parents' human capital upon the human capital of their offspring, by distinguishing the intra-family skill externalities from the influence of parents' income. Human capital is not measured by schooling years but by its market value calculated from the results of a wage equation. As regards the first point, our main findings are (i) that, compared to the lowest skill level, the skill premium generated by the Baccalaureate (henceforth ' $b a c$ ') has critically declined since the mid-seventies, and (ii) that the premium generated by higher education in relation to the level of the bac has increased, but this increase is not sufficient to offset the decline in the return to the bac. Consequently, France has experienced a general decrease in its skill premia. Concerning the second point, our calculations reveal that the impact of the family backgrounds upon the individuals' skill has critically increased from 1993 to 2003, this increase essentially deriving from a higher impact of parental income upon the educational attainment. At the same time, the impact of public educational expenditure has also increased.

In Section 2, we build the structural framework which is subsequently transformed into an empirical model utilised for the estimations. Section 3 describes the data and Section 4 the construction of the variables and the econometric methods. The results are exposed and discussed in Section 5. We conclude in Section 6.

\section{The model}

We construct the theoretical framework from which we subsequently derive the empirical model that is estimated in the following sections.

\subsection{The theoretical model}

We develop a theoretical framework which synthesises the two main channels through which the parents influence their children's skill, i.e., their income on the one hand and the human capital intra-family externality and transfers on the other. These generate an intergenerational transmission of human capital and a persistence of skill discrepancies across the dynasties. 


\section{Human capital and income}

We assume that a working individual is paid in proportion to her/his human capital. Denoting $W$ the wage per unit of human capital and $H_{i}$ the amount of human capital possessed by individual $i$, her/his wage $W_{i}$ is:

$$
W_{i}=W \times H_{i}
$$

The individual's human capital is fully determined by her/his course of study. This course of study consists of an ordered succession of education cycles such that an individual who wants to enter cycle $k$ must have successfully completed all the preceding cycles.

Each cycle provides a specific contribution to the accumulation of human capital. By assuming a continuum of cycles over the interval $[0, \bar{k}]$, individual $i$ ' s human capital is:

$$
h_{i}=\int_{0}^{k_{i}} a(k) d k
$$

where $h_{i}$ is the logarithm of individual $i$ 's human capital $H_{i}$, and $k_{i}$ the highest education cycle completed by this individual.

Coefficient $a(k)$ measures the contribution of the $k$-th cycle to the human capital accumulated by the individual. This signifies that the different cycles provide different return in terms of human capital. The higher $a(k)$ the more skill-enhancing cycle $k$ is. We assume $a(0)=0$, which indicates that an individual cannot have a human capital lower than 1 .

By combining equations (1) and (2) we obtain:

$$
W_{i}=W \times \exp \left[\int_{0}^{k_{i}} a(k) d k\right]
$$

\section{Education function}

There is a continuum of possible skills over the interval $[1, \bar{H}]$ with $\bar{H}=\exp \left[\int_{0}^{\bar{k}} a(k) d k\right]$.

The human capital that individual $i$ can acquire depends (i) on her/his effort $E_{i}$ in studying, (ii) on her/his parents' income $R_{i,-1}$ which measures the family's financial contribution to her/his education (subscript -1 denotes the preceding generation), (iii) on her/his parents human capital $H_{i,-1}$ through intra-family human capital externalities, and (iv) on the public expenditure for education from which s/he benefits. The amount of public 
educational services $G_{i}$ received by individual $i$ depends on her/his course of study, i.e., on the efficiency of the public expenditure allowed for each of the successive cycles completed by the individual, and thus on the level of human capital $H_{i}$ s/he acquires at the end of her/his schooling time. Hence: $G_{i}=G\left(H_{i}\right)$. The education function, assumed to be log-linear, can thus be written:

$$
H_{i}=A E_{i}^{\gamma_{0}} H_{i,-1}^{\gamma_{1}} R_{i,-1}^{\gamma_{2}}\left(G\left(H_{i}\right)\right)^{\gamma_{3}}
$$

The expression $A\left(G\left(H_{i}\right)\right)^{\gamma_{3}}$ depicts the efficiency of public education in all the cycles followed by the individual during her/his course of study.

Relation (4) can be expressed as:

$$
E_{i}=A^{-1 / \gamma_{0}} H_{i,-1}^{-\gamma_{1} / \gamma_{0}} R_{i,-1}^{-\gamma_{2} / \gamma_{0}}\left(G\left(H_{i}\right)\right)^{-\gamma_{3} / \gamma_{0}} H_{i}^{1 / \gamma_{0}}
$$

\section{Educational choice}

The individual's utility depends positively on her/his future income that is directly linked to her/his human capital $H_{i}$, and negatively on her/his education effort $E_{i}$.

We assume the following simple utility function:

$$
u_{i}=\left(W H_{i}\right)^{\alpha}-\delta E_{i}^{\beta}, \quad 0<\alpha \leq 1, \quad \beta \geq 1
$$

The utility function (6) is rather general. It stipulates that utility depends (i) positively on income $\mathrm{WH}_{i}$ with the marginal utility of income decreasing or constant, and (ii) negatively on the studying effort $E_{i}$ with the marginal disutility of effort increasing or constant. Coefficient $\delta$ depicts the effort aversion that is assumed identical across individuals.

The individual maximises her/his utility subject to the inverted education function (5).

The resulting optimal human capital of the individual is (see Appendix 1):

$$
H_{i}=C W^{\frac{\alpha \gamma_{0}}{\beta-\alpha \gamma_{0}}} H_{i,-1}^{\frac{\beta \gamma_{1}}{\beta-\alpha \gamma_{0}}} R_{i,-1} \frac{\beta \gamma_{2}}{\beta-\alpha \gamma_{0}} G_{i}^{\frac{\beta \gamma_{3}}{\beta-\alpha \gamma_{0}}}
$$

where $G_{i}=G\left(H_{i}\right), \quad C=\left(\frac{\alpha \gamma_{0} A^{\beta / \gamma_{0}}}{\beta \delta\left(1+\gamma_{3} \varepsilon_{G / H}\right)}\right)^{\frac{\gamma_{0}}{\beta-\alpha \gamma_{0}}}$, and $\varepsilon_{G / H}=\frac{\partial G / G}{\partial H_{i} / H_{i}}$ is the elasticity of $G\left(H_{i}\right)$ in relation to the human capital level. We assume that this elasticity is constant and lower than 1. 


\subsection{The empirical model}

The model constructed in Subsection 2.1 provides:

1) A simple relation between earnings and the accumulated human capital (Relation 1).

2) A measure of the individual skill as a combination of successive education cycles that bring uneven contributions to the wage value of the human capital (Relations 2 and 3);

3) A determination of the human capital chosen by the individual that depends on parental characteristics and on the educational policy (Relation 7).

From this model, the impact of the parents' skill upon the children's skill can be estimated in two stages:

1) Firstly, estimating Relation (3) makes it possible to determine the wage value of the human capital of each educational cycle and thus of each individual.

2) Once calculated this human capital value, estimating (7) provides (i) the impact of the parents' human capital upon the children's human capital and (ii) the division of this impact between two components, one linked to the parents' income and the other to intra-family externalities.

\section{First stage: estimating human capital from a wage equation}

Modifications. We modify Equation (3) that binds wage to human capital in two ways. We firstly move from a continuum to a limited number of education cycles. In addition, we account for certain determinants of wage other than human capital.

Relation (2) assumes a continuum of educational cycles. Consequently, human capital is a continuous variable over the interval $[1, \bar{H}]$. In practical terms, there are a limited number of stages in the individual's course of study. The related human capital (skill) is thereby a discrete variable with a limited number of possible values. So as to account for this, we modify Equations (2) and (3) as follows:

$$
\begin{aligned}
& h_{i}=\sum_{k=1}^{\bar{k}} a_{k} e_{i k} \\
& w_{i}=w+\sum_{k=1}^{\bar{k}} a_{k} e_{i k}
\end{aligned}
$$

where $\bar{k}$ is the highest possible number of educational cycles and $e_{i k}=1,0$ according to whether individual $i$ has completed cycle $k$ or not. 
In addition, Equations (3) and (3') assume (i) that human capital is the only determinant of labour efficiency, and (ii) that the labour market is perfectly competitive. Relaxing these assumptions, we now introduce the following additional variables which impact upon wages:

1) Certain individual characteristics that influence earnings for objective reasons (experience, time-related obsolescence, training etc.) or socio-cultural prejudice (gender, race, foreign origins etc.).

2) Certain characteristics related to the firm (size, location etc.) or to the industry which cause wage discrepancies when markets are not perfectly competitive.

The impact of these two sets of characteristics on individual $i$ 's wage is denoted by the variable $\Omega_{i}$ defined as follows:

$$
\omega_{i}=\sum_{j} b_{j} \omega_{i j}
$$

where $\omega_{i}$ is the logarithm of $\Omega_{i}, b_{j}$ is the impact of characteristic $j$ and $\omega_{i j}=1,0$ according to whether individual $i$ possesses this characteristic or not.

As a consequence, the wage equation (1) is modified in the following way:

$$
W_{i}=W \Omega_{i} H_{i}
$$

The estimated wage equation. By inserting (2') and (8) into the logarithm of (9), we obtain the following relation: $w_{i}=w+\sum_{k=1}^{\bar{k}} a_{k} e_{i k}+\sum_{j} b_{j} \omega_{i j}$. The stochastic form of this model is:

$$
w_{i}=w+\sum_{k=1}^{\bar{k}} a_{k} e_{i k}+\sum_{j} b_{j} \omega_{i j}+\mu_{i}
$$

where $\mu_{i}$ is the error term that encompasses all the unobservable characteristics, $e_{i k}$ and $\omega_{i j}$ are dummies equal to 1 when the individual has completed the education cycle $k$ or possesses the characteristic $j$, and 0 in the opposite case; $w$ is the wage of reference.

The estimation of Equation (10) makes it possible to calculate the vector $a^{\prime}=\left(a_{1}, a_{2}, \ldots, a_{\bar{k}}\right)$ of the contribution of each education cycle to the accumulation of human capital. Individual $i$ who has completed the course of study $e_{i}{ }^{\prime}=\left(e_{i 1}, e_{i 2}, \ldots, e_{i \bar{k}}\right), e_{i k}=0,1$, possesses the human capital (in logarithm):

$$
h_{i}=a \times e_{i}
$$


Equation (11) shows that two individuals who pursue the same course of study possess the same human capital, i.e., each course of study determines one unique level of human capital. It should be remembered that what is calculated here is the economic value of each cycles. Human capital is thus measured in terms of its return in the labour market.

At the end of this first stage, we can assign to each individual of our sample the human capital measure which corresponds to her/his course of study.

\section{Second stage: estimation of the education function}

We start from Equation (7): $H_{i}=C W^{\frac{\alpha \gamma_{0}}{\beta-\alpha \gamma_{0}}} H_{i,-1} \frac{\beta \gamma_{1}}{\beta-\alpha \gamma_{0}} R_{i,-1} \frac{\beta \gamma_{2}}{\beta-\alpha \gamma_{0}} G\left(H_{i}\right)^{\frac{\beta \gamma_{3}}{\beta-\alpha \gamma_{0}}}$.

The variables $H_{i}$ and $H_{i,-1}$, i.e., the individual's and her/his parent's human capital, are calculated from their courses of study as defined by Equation (11).

The parents' income. The parents' income is measured by the father's wage (see the explanation below), which can be written because of (1) and (9):

$$
R_{i,-1}=W_{i,-1}=W_{-1} \Omega_{i,-1} H_{i,-1}
$$

with $\Omega_{i,-1}=\prod_{j}\left(\Omega_{i,-1, j}\right)^{b_{j}}=\frac{W_{i,-1}}{W_{-1} H_{i,-1}}$ (from Equation 9) and subscript -1 indicates parents' values.

Equation (7) cannot be estimated directly because the father's income depends on his human capital (Equation 12), which implies that the variables $R_{i,-1}$ and $H_{i,-1}$ are correlated.

By inserting (12) into (7) and after simplification we obtain:

$$
H_{i}=\mathrm{A}_{0} H_{i,-1}^{\alpha_{1}} \Omega_{i,-1}^{\alpha_{2}} G_{i}^{\alpha_{3}}
$$

with: $\quad \mathrm{A}_{0}=W_{-1}^{\frac{\beta \gamma_{2}}{\beta-\alpha \gamma_{0}}} C ; \quad \alpha_{1}=\frac{\beta\left(\gamma_{1}+\gamma_{2}\right)}{\beta-\alpha \gamma_{0}} ; \quad \alpha_{2}=\frac{\beta \gamma_{2}}{\beta-\alpha \gamma_{0}} ; \quad \alpha_{3}=\frac{\beta \gamma_{3}}{\beta-\alpha \gamma_{0}}$.

In Equation (13), the individual's human capital depends on 3 determinants: her/his parent's human capital $\left(H_{i,-1}\right)$, the characteristics of her/his parent's wage except human capital $\left(\Omega_{i,-1}\right)$, and the public expenditure corresponding to her/his course of study $\left(G_{i}\right)$. The coefficient $\alpha_{1}=\frac{\beta\left(\gamma_{1}+\gamma_{2}\right)}{\beta-\alpha \gamma_{0}}$ measures the total impact of the parents' skill upon the child's 
skill. This total impact can be divided between two effects (equation 7), i.e., (i) an intrafamily externality effect $\frac{\beta \gamma_{1}}{\beta-\alpha \gamma_{0}}=\alpha_{1}-\alpha_{2}$ and (ii) a parents' income effect $\alpha_{2}=\frac{\beta \gamma_{2}}{\beta-\alpha \gamma_{0}}$.

Note that, since $\Omega_{i,-1}$ is equal to the ratio of the parent's wage divided by the wage corresponding to their skill acting alone $\left(\Omega_{i,-1}=W_{i,-1} / W_{-1} H_{i,-1}\right)$, an indicator of ratio $W_{i,-1} / W_{-1} H_{i,-1}$ is sufficient to calculate $\Omega_{i,-1}$.

The variable $\boldsymbol{G}_{i}, G_{i}$ depicts the impact of public expenditure in the educational cycles followed by individual $i$ upon her/his human capital. We assume the following indicator $G_{i}$ for an individual who has attained the skill level $k_{i}$ :

$$
G_{i}=G\left(k_{i}\right)=\sum_{k=1}^{k_{i}} n_{k} \frac{D_{k i}}{N_{k i}}
$$

with $n_{k}$ the number of years necessary to complete cycle $k, D_{k i}$ the yearly public spending allocated to cycle $k$ when individual $i$ was participating in this cycle and $N_{k i}$ the average yearly number of pupils in $k$ at the time when individual $i$ followed cycle $k$ (the expenditure and the number of pupils/students in each cycle change every year). The precise method of calculation of $G_{i}$ used in the estimations is described in Subsection 4.2.

The estimated relation. By log-linearising function (13) we obtain:

$$
h_{i}=\alpha_{0}+\alpha_{1} h_{i,-1}+\alpha_{2} \omega_{i,-1}+\alpha_{3} g_{i}
$$

with $\omega_{i,-1}=\log \left(\frac{W_{i,-1}}{W_{-1} H_{i,-1}}\right)$ and $g_{i}=\log G_{i}$.

Note that, since $W$ is the same for all individuals, the $\log$ of $W^{\frac{\alpha \gamma_{0}}{\beta-\alpha \gamma_{0}}}$ in equation (7) is included in the constant term $\alpha_{0}$.

The preceding equation can be expressed in the stochastic form (with $v_{i}$ the error term):

$$
h_{i}=\alpha_{0}+\alpha_{1} h_{i,-1}+\alpha_{2} \omega_{i,-1}+\alpha_{3} g_{i}+v_{i}
$$

Equation (15) can be estimated using cross section of individuals. 


\section{The data}

\subsection{Database}

The data used for the microeconometric estimations are taken from the French surveys Formation Qualification Professionnelle (FQP) constructed by the INSEE in 1977, 1985, 1993 and 2003. These surveys provide a large number of characteristics for individuals over 16 y.o. (20 y.o. in 2003) belonging to households, and for their parents.

In stage 1, we estimate a wage equation for those individuals who occupy jobs which are both gainful and full time. These features require the removal of a number of observations as depicted in Table 1.

Table 1. The Sample

\begin{tabular}{lrrrr}
\hline & 1977 & 1985 & 1993 & \multicolumn{1}{c}{2003} \\
\hline Total sample & 32078 & 30387 & 10479 & 15727 \\
Removed observations & 8709 & 9296 & 1875 & 5067 \\
Selected sample & 23369 & 21091 & 8604 & 10660 \\
\hline
\end{tabular}

In stage 2, we estimate an education function in which an individual's human capital depends on her/his parents' human capital and income, and on the public expenditure the individual benefits from, depending on the stages of study s/he has followed.

The parents are identified by the father because of the availability in the database of the variables required for the estimations.

In addition, we must utilise data from the 1977 and 1985 surveys to approximate the father's income in 1993 and 2003 (see the method in Subsection 4.2.), which restricts the education function estimations to these last two years.

To calculate the public expenditure an individual benefits from during her/his course of study, we need the expenditure allocated to each cycle when the individual was at school. As data on public expenditure for education are not available before 1974, this expense will be approximated by the number of professors in each level, provided by the INSEE ${ }^{2}$. Given that these data are not available before 1948, the estimations are implemented for individuals between 20 and 50 years of age ${ }^{3}$. Consequently, the estimation of the education function is carried out from a sample of 6261 individuals in 1993, and 7303 in 2003.

\footnotetext{
${ }^{2}$ From the Annuaire rétrospectif (INSEE) for the years 1948-1988, and the Annuaire for the years 1989-1993.

${ }^{3}$ A precise presentation of the variable 'public expenditure' is provided in Subsection 4.2.
} 


\subsection{Educational levels (skills)}

From the French database FQP, we build a classification of ten levels (courses of studies) and ranked in ascending order of skill. The succession of levels is depicted in Figure 1.

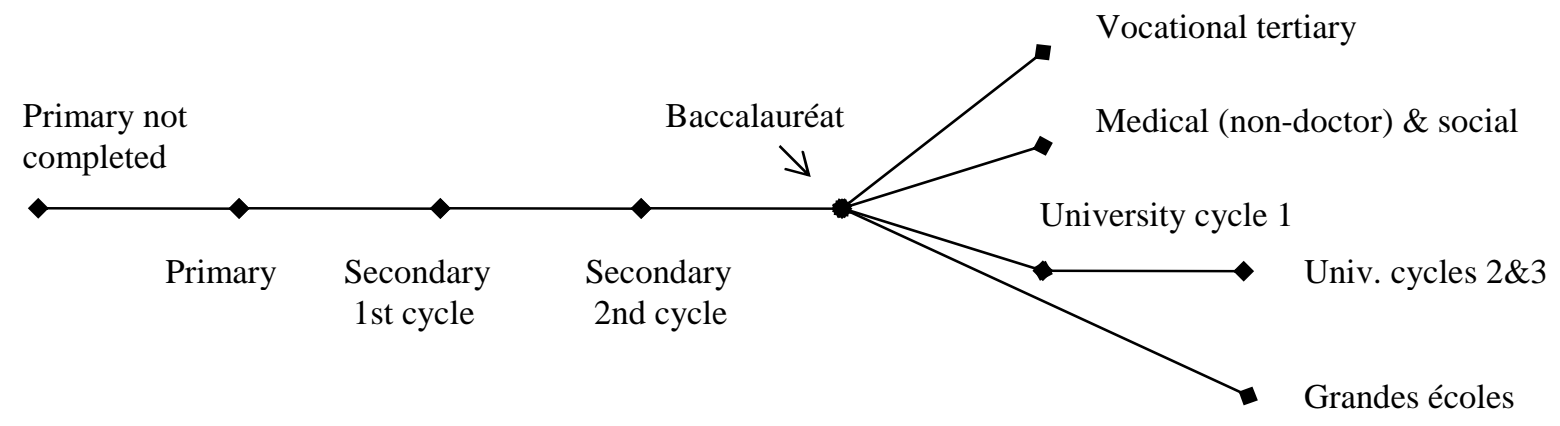

Figure 1. The structure of the educational system

Each individual in the sample is defined by the succession of cycles s/he has followed, and finally by the highest level s/he has achieved. The distribution of individuals between the ten possible levels is depicted in Table 2 for each year.

Table 2: The education levels and their weight (\%)

\begin{tabular}{|c|c|c|c|c|}
\hline & 1977 & 1985 & 1993 & 2003 \\
\hline 1.Primary education not completed (lowest skill) & 22,41 & 17,77 & 16,96 & 16,05 \\
\hline 2.Primary education completed & 25,75 & 17,81 & 12,15 & 6,28 \\
\hline 3. Secondary education $1^{\text {st }}$ cycle & 28,19 & 35,24 & 38,08 & 34,66 \\
\hline 4. Secondary education cycle 2 & 4,52 & 3,63 & 2,28 & 4,24 \\
\hline 5. Baccalauréat & 7,17 & 9,35 & 11,94 & 12,71 \\
\hline 6. University $1^{\text {st }}$ cycle ( 2 years) & 2,33 & 2,75 & 2,40 & 1,84 \\
\hline 7. Vocational tertiary (BTS, DUT) & 1,32 & 3,28 & 4,66 & 8,25 \\
\hline 8. Medical \& social degree lower than doctor degree & 0,91 & 1,34 & 1,59 & 1,64 \\
\hline 9. University cycles 2 or 3 & 4,62 & 5,96 & 5,56 & 11,50 \\
\hline 10.Grandes écoles & 2,78 & 2,86 & 2,38 & 2,82 \\
\hline TOTAL & $100 \%$ & $100 \%$ & $100 \%$ & $100 \%$ \\
\hline Number of observations & 23369 & 21091 & 8604 & 10660 \\
\hline
\end{tabular}

Compared to other countries, the French educational system presented several specificities in the years when the individuals were schooled. Firstly, there was a special degree two years after university entrance (the DEUG), which corresponded to the first cycle of university. This was subsequently discontinued when the European system was implemented. In addition, France's Grandes Ecoles are very selective tertiary establishments which aim at producing a French elite in high level engineering and business administration. This system is still operative. Finally note that we put together both the $2^{\text {nd }}$ and $3^{\text {rd }}$ cycles of university studies because the sample fails to make this distinction for the individuals' fathers. 


\section{$4 \quad$ Methods and variables}

We estimate a two-stage econometric model. The first stage determines the value of the human capital linked to each education level from a (mincerian) wage equation. At the second stage, the value of each education level (skill) as determined in stage 1 is utilised to estimate the elasticity of the individual's skill in relation to her/his parent's skill, to her/his parents' income and to the public education expenditure.

\subsection{First stage: estimation of the wage equation}

The explained variable of the wage equation is the (log of the) monthly wage for full time workers. This creates a self-selection bias: the wages and individual characteristics are only selected for full time working wage earners. In this case, the OLS method provides biased estimations. This selection bias can be treated through the Heckman selection model. The Heckman selection model (Gronau, 1974; Lewis, 1974; Heckman, 1976 and 1979) assumes an underlying relationship between two regressions: the outcome equation (the wage equation here) and the selection equation. This model is estimated in one step by using maximum likelihood methods to estimate simultaneously both equations. Estimating maximum likelihood ${ }^{4}$ has two advantages: it is more efficient and the variances are easier to calculate.

\section{The selection equation}

Individual $i$ 's wage is selected only if individual $i$ is a full time worker, i.e., under the following condition (selection equation):

$$
P_{i}^{*}=z_{i} \eta+\mu_{0 i}, \quad P_{i}= \begin{cases}1 & \text { if } P_{i}^{*}>0 \\ 0 & \text { if } P_{i}^{*} \leq 0\end{cases}
$$

$P_{i}^{*}$ is the probability of being a full time wage earner. $z_{i}$ is the vector of explanatory variables utilised in the selection equation (Table A1 in Appendix 4) and $\mu_{0 i}$ is the error term. We add an instrumental variable that is linked to the probability of participating in the labour market and being a full time wage earner, but bears no influence on the level of wage. This instrumental variable is the presence in the household of children of less than 6 years old. As a matter of fact, this presence could lower the probability of participating in the labour market, and especially the probability of choosing a full time job.

\footnotetext{
${ }^{4}$ It corresponds to partial maximum likelihood because the observations of individuals who do not occupy a full time job do not contribute to the likelihood function for observed wages.
} 
The outcome equation (wage equation) is:

$$
w_{i}=\left\{\begin{array}{cl}
a_{0}+\sum_{k=1}^{\bar{k}} a_{k} e_{i k}+\sum_{j} b_{j} \omega_{i j}+\mu_{i} & \text { if } P_{i}^{*}>0 \\
- & \text { if } P_{i}^{*} \leq 0
\end{array}\right.
$$

$w_{i}$ is the $\log$ of individual $i$ 's monthly wage, $e_{i k}=1,0, k=1 \ldots \bar{k}$ are the successive cycles s/he has followed, the $\omega_{i j}$ s her/his personal characteristics, and $\mu_{i}$ is the error term.

The variables $\omega_{i j}$ selected for the wage equation are depicted in Table 3. These comprise age, gender, nationality, marital status, experience, obsolescence, working district, working sector, and variables indicating the participation in training programmes ${ }^{5}$. Concerning these variables, we introduce (i) dummies for the skill level obtained at the end of the training programme when this level is higher than the skill at the end of initial education and (ii) an additional dummy that accounts for training when this yields a skill level which is not higher than that obtained at the end of initial schooling.

Table 3. Explanatory variables in the wage equation (except the skill levels)

\begin{tabular}{|l|l|}
\hline \multicolumn{1}{|c|}{ Variables } & \multicolumn{1}{c|}{ Definition } \\
\hline Gender & Female / Male \\
\hline Marital status & 4 cases: Married / Single / Widowed / Divorced \\
\hline Nationality & 3 cases: French / naturalized French / Foreign \\
\hline Working sector & 11 sectors \\
\hline Working district size & 9 sizes \\
\hline Training & 11 levels (see explanation above) \\
\hline Age & \\
\hline Experience & Number of years in work \\
\hline Obsolescence & Square of the number of years in work \\
\hline
\end{tabular}

Finally, the estimation of the wage function provides the vector $\hat{a}^{\prime}=\left(\hat{a}_{1}, \hat{a}_{2}, \ldots, \hat{a}_{\bar{k}}\right)$ of the contribution of each cycle to the human capital value. As a consequence, this makes it possible to calculate the wage value of one individual's human capital (skill) once her/his course of study $e_{i}{ }^{\prime}=\left(e_{i 1}, e_{i 2}, \ldots, e_{i k}\right), e_{i k}=0,1$, is known.

\subsection{Second stage: estimation of the education function}

In stage 2, we estimate the education function (15) in which the individual's skill level depends on her/his father's skill level, on her/his father's income (excluding the impact of human capital), and on the public education expenditure s/he has benefited from:

\footnotetext{
${ }^{5}$ Antonelli et al. (2010) point to the importance of on-the-job training, particularly in innovative contexts.
} 


$$
\hat{h}_{i}=\alpha_{0}+\alpha_{1} \hat{h}_{i,-1}+\alpha_{2} \omega_{i,-1}+\alpha_{3} g_{i}+v_{i}
$$

The skill levels

$\hat{h}_{i}$ is (the logarithm of) the individual's human capital and $\hat{h}_{i,-1}$ that of her/his father. Both $\hat{h}_{i}$ and $\hat{h}_{i,-1}$ are obtained by multiplying the vectors $\hat{a}^{\prime}$ and $e_{i}\left(e_{i,-1}\right.$ for the father):

$$
\hat{h}_{i}=\hat{a} \times e_{i}
$$

with $e_{i}{ }^{\prime}=\left(e_{i 1}, e_{i 2}, \ldots, e_{i \bar{k}}\right), e_{i k}=0,1$, the vector of the course of study followed by individual $i$, and $\hat{a}^{\prime}=\left(\hat{a}_{1}, \hat{a}_{2}, \ldots, \hat{a}_{\bar{k}}\right)$ the vector of the value of each cycle estimated in stage 1 .

Equation (18) shows that two individuals who pursue the same course of study possess the same skill level. Each combination of successive education cycles determines one unique level of human capital.

The father's human capital is calculated in the same way as the individual's skill level: $\hat{h}_{i,-1}=\hat{a}^{\prime} \times e_{i,-1}$. So as to have comparable values of the human capital for both the individual and her/his father, the vector $\hat{a}^{\prime}$ applied to the father's course of study $e_{i,-1}$ is the vector calculated for his child.

\section{The father's income}

To estimate the impact of the father's income, we use the indicator $\Omega_{i,-1}=W_{i,-1} / W_{-1} H_{i,-1}$, with $W_{i,-1}$ the father's income and $W_{-1} H_{i,-1}$ the income resulting from his human capital alone. $\Omega_{i,-1}$ measures the determinants of the wage excluding the human capital (Subsection 2.2).

The database provides no information on fathers' incomes, but it provides their professional occupations (6 categories, see Appendix 2). We thereby approximate the father's income by the average income corresponding to his profession.

Since we do not know $W_{-1}, W_{-1} H_{i,-1}$ is approximated by the average wage corresponding to the father's skill level. As a consequence:

$$
\omega_{i,-1}=\log \left(\Omega_{i,-1}\right)=\log \left(\frac{\text { average wage for } i \text { 's professional occupation }}{\text { average wage for } i \text { 's skill level }}\right)
$$

\section{Public educational expenditure}

Variable $g_{i}$ is the $\log$ of $G_{i}=G\left(k_{i}\right)$, with $i$ depicting the individual and $k_{i}$ his/her highest completed cycle. $G_{i}$ depends on both the cycles followed by individual $i$ and the years when 
s/he followed these cycles. More precisely, $G_{i}$ is the sum of the public expenditure per pupil in the cycle followed by the individual for each of her/his schooling years, i.e., the sum for all her/his schooling years of the dated ratios $R_{t, c}=D_{t, c} / N_{t, c}$ where $D_{t, c}$ and $N_{t, c}$ are respectively the public expenditure and the number of pupils/students in cycle $c$ at year $t$, provided that the individuals followed cycle $c$ at year $t$. As data on public expenditure for education are not available before 1974, we approximate $D_{t, c}$ by the number of teachers within each cycle for each year. This also allows the measurement of real public spending, i.e. to account for price changes.

For each individual, we calculate the sum of these ratios within each cycle s/he has followed and each year s/he has spent in this cycle.

As an example, let us consider an individual of 48 years old in 1993. S/he was born in 1945 and started primary school in 1950 . If this individual has an University $2^{\text {nd }}$ cycle (two years) degree, then s/he pursued her/his first cycle from 1950 to 1955, her/his secondary cycle from 1956 to 1963 and her/his University cycle from 1964 to 1968 (see Appendix 3). Consequently, her/his $G_{i}$ is: $G_{i}=\sum_{t=1950}^{1955} R_{t, \text { primary }}+\sum_{t=1956}^{1963} R_{t, \text { sec ondary }}+\sum_{t=1964}^{1968} R_{t, \text { university }}$.

To calculate the ratio $R_{t, c}$, we have utilised data from the Annuaire retrospectif provided by the French INSEE. As the data are not available before 1948, we only consider individuals until 50 years old in both years 1993 and in $2003^{6}$.

\section{The estimated education function}

We estimate the education function $h_{i}=\alpha_{0}+\alpha_{1} h_{i,-1}+\alpha_{2} \omega_{i,-1}+\alpha_{3} g_{i}+v_{i}$, with $h_{i}$ the logarithm of the individual's human capital, $h_{i,-1}$ the logarithm of her/his father's human capital, $\omega_{i,-1}$ the logarithm of the father's income, $g_{i}$ the logarithm of the public expenditure for the individual $i$ ' s education, and $v_{i}$ the error term.

Coefficient $\alpha_{1}=\frac{\beta\left(\gamma_{1}+\gamma_{2}\right)}{\beta-\alpha \gamma_{0}}$ measures the total impact of the parent's human capital upon the child's skill. This impact may be divided between two effects: the intra-family effect $\frac{\beta \gamma_{1}}{\beta-\alpha \gamma_{0}}=\alpha_{1}-\alpha_{2}$ and the parent's income effect $\alpha_{2}=\frac{\beta \gamma_{2}}{\beta-\alpha \gamma_{0}}$. Finally, $\alpha_{3}=\frac{\beta \gamma_{3}}{\beta-\alpha \gamma_{0}}$ is the elasticity of the individual's skill in relation to public education expenditure.

\footnotetext{
${ }^{6}$ A 50 year old individual in 1993 was born in 1943 and started primary school in 1948.
} 
A problem of heteroscedasticity may arise from the estimation of the education function because we utilise a limited amount of skill levels and the skill indicator is thus discontinuous. We use a Breusch-Pagan test to verify heteroscedasticity. The results lead to rejecting the null hypothesis of homoscedasticity ${ }^{7}$. Contrary to the OLS estimator, the variance of this estimator is biased. We thus correct the variance-covariance matrix by using White's correction ${ }^{8}$. This correction provides a convergent estimation of the variance-covariance matrix of the estimated coefficients with robust standard errors.

\section{$5 \quad$ Results}

\subsection{Wage equations}

The overall results of the estimated wage equations are provided in Appendix 4. All the variables display the expected sign. In this section, we draw attention to the skill premia that are calculated from the coefficients of the wage equations.

Table 4. The skill premia

\begin{tabular}{|c|c|c|c|c|c|c|c|c|c|c|c|c|}
\hline \multirow{2}{*}{ Skill level } & \multicolumn{3}{|c|}{1977} & \multicolumn{3}{|c|}{1985} & \multicolumn{3}{|c|}{1993} & \multicolumn{3}{|c|}{2003} \\
\hline & SP1 & SP2 & SP3 & SP1 & SP2 & SP3 & SP1 & SP2 & SP3 & SP1 & SP2 & SP3 \\
\hline Primary not completed & 1 & 1 & & 1 & 1 & & 1 & 1 & & 1 & 1 & \\
\hline Primary co & 1.14 & 1.14 & & 1.10 & 1.10 & & 1.04 & 1.04 & & 1.07 & 1.07 & \\
\hline Secon & 1.35 & 1.18 & & 1.27 & 1.15 & . & 1.22 & 1.16 & & 1.20 & 1.12 & \\
\hline & 59 & 1.18 & & 1.45 & 1.14 & & 1.31 & 1.07 & & 1.30 & 1.08 & \\
\hline & 1.74 & 1.09 & 1 & 1.54 & 1.06 & 1 & 1.46 & 1.11 & 1 & 1.40 & 1.07 & 1 \\
\hline Unive & 1.85 & 1.05 & 1.05 & 1.61 & 1.04 & 1.04 & 1.53 & 1.05 & 1.05 & 1.53 & 1.09 & 1.09 \\
\hline Vocational tertiary & 1.97 & 1.13 & 1.13 & 1.80 & 1.16 & 1.16 & 1.70 & 1.16 & 1.16 & 1.68 & 1.20 & 1.20 \\
\hline Medical \& S & 1.83 & 1.04 & 1.04 & 1.70 & 1.10 & 1.10 & 1.70 & 1.16 & 1.16 & 1.65 & 1.18 & 1.18 \\
\hline University $2^{\text {nd }} \& 3$ rd cycles & 2.35 & 1.27 & 1.34 & 2.11 & 1.30 & 1.36 & 2.05 & 1.33 & 1.40 & 1.99 & 1.29 & 1.42 \\
\hline Grandes écoles & 2.84 & 1.62 & 1.62 & 2.62 & 1.69 & 160 & 2.65 & 1.81 & 181 & 239 & 1.70 & 1.70 \\
\hline
\end{tabular}

Remark : For all the levels of tertiary education, the marginal skill premia (SP2) are calculated in relation to the bac, except for the University $2^{\text {nd }} \& 3^{\text {rd }}$ cycles for which the reference is the University $1^{\text {st }}$ cycle.

A skill premium is the ratio of the wage value of a certain level of skill in relation to another level taken as a benchmark. Table 4 describes three types skill premia (henceforth SP). The precise calculation of the three types of skill premium is described in Appendix 5 . For each level of skill, SP1 is the skill premium of this level in relation to the lowest skill, i.e., primary education not completed. SP2 is the marginal skill premium. For each skill level, SP2

\footnotetext{
${ }^{7}$ We obtain $\chi^{2}(1)=350.29$ and Prob $>\chi^{2}=0.000$ for the equation estimated in 1993, and $\chi^{2}(1)=258.85$ and Prob> $\chi^{2}=0.000$ for 2003 .

${ }^{8}$ White's test is available upon request.
} 
provides the skill premium of this level in relation to the level just before it. Finally, SP3 provides the skill premium of each skill above the bac in relation to the skill corresponding to the bac, i.e., the ratio $\mathrm{SP}_{k} / \mathrm{SP}_{b a c}$ for all the courses of study $k$ higher than the bac.

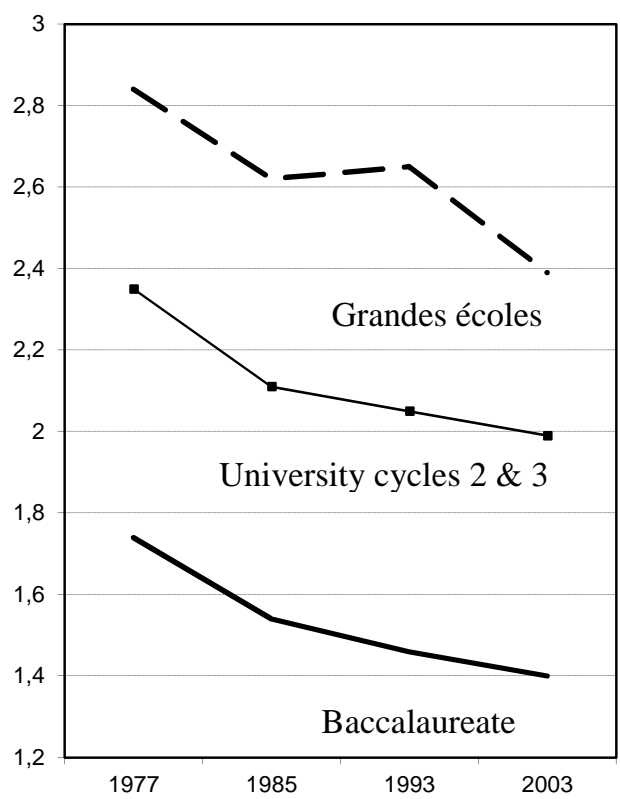

Figure 2. The skill premia (SP1)

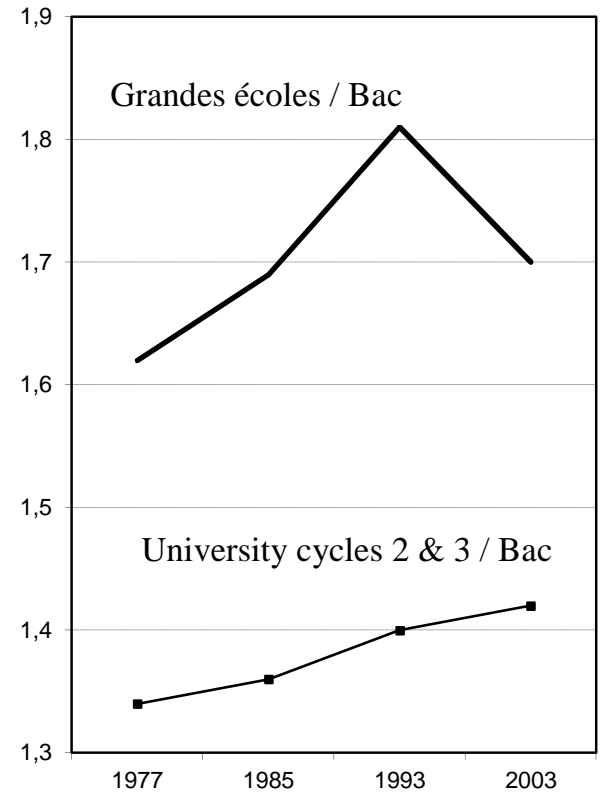

Fig 3. The skill premia / bac (SP3)

From these results, we infer two major developments:

1) All the skill premia (in relation with the lowest skill) decrease over time (Figure 2). This result is in line with all the indicators of inequality that decrease in France over the given period (e.g., earnings D9/D1 calculated by the OECD; share of Q5/Q1 and Gini provided by Eurostat for individual incomes etc.).

2) The decrease is totally attributable to the lowest skills, i.e., these skills up to the bac. In particular, the skill premium linked to the accession to the bac diminishes from 1.74 in 1977 to 1.40 in 2003. Contrarily, the skill premia of the different higher degrees in relation to the bac increase over time (Figure 3). However, these increases are not sufficient to offset the decrease in the lowest skill premia.

We can make the following two additional remarks:

1) The decrease in the skill premium of the Grandes Ecoles (in relation to the bac) between 1993 and 2003 could derive from the fact that new and less prestigious establishments were inserted into this group in 2003.

2) The skill premia calculated here may appear rather weak compared to the usual measures of inequality (for instance, the D9/D1 ratio calculated by the OECD for France is equal to 3.03 in 2003). This derives from the fact that several determinants of wage inequality 
such as experience, gender, location, etc. are not included in our skill premia that only measure the impact of (initial) education upon wage.

\subsection{Education function}

Table 5 depicts the result of the education function estimations, and table 6 the decomposition of the total family impact between the intra-family skill externality and the influence of the family income.

Table 5: Education function estimation (OLS with White's correction)

\begin{tabular}{|l|c|c|c|c|}
\hline & \multicolumn{4}{|c|}{ Skill of the child } \\
\hline & \multicolumn{2}{|c|}{1993} & \multicolumn{2}{c|}{2003} \\
\hline Variables & Coefficient & Stand. err & Coefficient & Stand. err \\
\hline Father's skill & $0.205^{* * *}$ & $(0.010)$ & $0.249^{* * *}$ & $(0.013)$ \\
\hline Father's income & $0.033^{* * *}$ & $(0.005)$ & $0.061^{* * *}$ & $(0.005)$ \\
\hline Public education expenditure & $0.500^{* * *}$ & $(0.006)$ & $0.673^{* * *}$ & $(0.007)$ \\
\hline constant & $0.566^{* * *}$ & $(0.005)$ & $0.593^{* * *}$ & $(0.005)$ \\
\hline $\mathrm{R}^{2}$ & \multicolumn{2}{|c|}{0.63} & \multicolumn{2}{c|}{0.65} \\
\hline Number of observations & \multicolumn{2}{|c|}{6793} & \multicolumn{2}{c|}{7683} \\
\hline
\end{tabular}

Table 6: Decomposition of the family impact

\begin{tabular}{|l|c|c|}
\hline & 1993 & 2003 \\
\hline Direct impact of father's skill level (intra-family externalities \& transfer) & 0.172 & 0.188 \\
\hline Impact of father's income & 0.033 & 0.061 \\
\hline Total father's influence & 0.205 & 0.249 \\
\hline
\end{tabular}

The estimations reveal three major changes from 1993 to 2003:

1) A substantial increase in the impact of intra-family factors, i.e., intra-family skill externalities and family income. The aggregated elasticity of the individual's skill in relation to her/his father's skill expanded from 0.205 in 1993 to 0.25 in 2003.

2) This increase in the impact of the family background upon the individual's education essentially derives from the influence of family income. This accounts for $16.1 \%$ of the total family influence (elasticity) in 1993, and for $24.5 \%$ in 2003 .

3) The impact of public education expenditure increases, with an elasticity that widened from 0.50 in 1993 to 0.673 ten years later.

Finally note that the constant has increased, which is as expected since the constant includes the impact of the real wage that increased from 1993 until 2003. 


\subsection{Discussion}

The estimated wage functions and education functions reveal several significant changes:

1) The wage values of all the skill levels up to the Baccalaureate have critically decreased over the period 1977-2003.

2) In relation to the bac, the wage values of all tertiary education levels rose, but this rise was not sufficient to offset the decrease in the skill premium of the bac. As a consequence, all the skill premia (in relation to the lowest skill) decreased throughout the period 19972003, which denotes a reduction in inequality.

3) The total impact of the family (father) upon the individuals' education attainments has significantly increased from 1993 to 2003, and this rise essentially derives from the family's income, albeit that the influence of intra-family skill externalities also increased.

4) The impact of public education expenditure on the individuals' educational attainment has increased. This shows that higher public expenditure for education could offset the increasing impact of the family.

Finally, our results draw a rather mixed picture that combines lower inequality -since the skill premia decreased - and lower social mobility - since the impact of family background increased. The first result could derive, at least partially, from labour market institutions, such as the minimum wage, which narrowed inequality in the short term, whereas the rising influence of family characteristics tended to perpetuate inequality in the longer term. However, the increase in the impact of public educational expenditure provides a tool to counteract the influence of family background.

\section{Conclusion}

We have estimated a structural model using French data (i) to measure the return to each skill level, and (ii) to evaluate the influence of the parents' human capital upon the human capital of their children. As regards this second point, the model makes it possible to distinguish between the two main channels through which the parents influence their children's skill: their income and the intra-family skill externalities. To measure human capital, we do not use the schooling years but its efficiency on the labour market resulting from the estimation of a wage equation.

We show that between 1977 and 2003, France underwent a general decrease in its skill premia due to the critical decline in the return to the bac. The skill premium of all tertiary 
education levels rose in relation to the level of the bac, but this increase was not sufficient to offset the decline in the skill premium of the bac. Finally, our estimations reveal lower social mobility since the influence of the family upon the individuals' skills critically increased from 1993 to 2003. At the same time, the impact of public educational expenditure also increased.

\section{References}

Acemoglu D. and J.S. Pischke (2001). Changes in the wage structure, family income, and children's education. European Economic Review, 45, 890-904.

Antonelli G., Antonietti R. and G. Guidetti (2010). Organizational change, skill formation, human capital measurement: evidence from Italian manufacturing firms. Journal of Economic Surveys, 24, 206-247.

Ashenfelter O. and A.B. Krueger (1994). Estimates of the Economic Return to Schooling from a New Sample of Twins. American Economic Review, 84(5), 1157-1173.

Becker G.S. and N. Tomes (1976). Child endowments and the quantity and quality of children. Journal of Political Economy, 84(4), S143-S162.

Becker G.S. and N. Tomes (1979). An equilibrium theory of the distribution of income and intergenerational mobility. Journal of Political Economy, 87, 1153-1189.

Becker G.S. and N. Tomes (1986). Human capital and the rise and fall of families. Journal of Labor Economics, 4, S1-S39.

Björklund A. and M. Jäntti (1997). Intergenerational Income Mobility in Sweden Compared to the United States, American Economic Review, 87(5), 1009-1018.

Björklund A. and M. Jäntti (2009). Intergenerational income mobility and the role of family background. In W. Salverda, B. Nolan, and T. Smeeding eds., Handbook of Economic Inequality. Oxford: Oxford University Press.

Black S. and P. Devereux (2011). Recent Developments in Intergenerational Mobility. In O. Ashenfelter and D. Card (eds.) Handbook of Labor Economics 4B (pp1487-541). Amsterdam: Elsevier, North-Holland.

Blanden J., Goodman A., Gregg P. and S. Machin (2004). Changes in intergenerational mobility in Britain. In M. Corak (ed.) Generational Income Mobility in North America and Europe. Cambridge University Press.

Blanden J. (2009). How much can we learn from international comparisons of intergenerational mobility?. Paper no. CEEDP0111, Centre for the Economics of Education, LSE.

Bowles S. and H. Gintis (2001). The Inheritance of Economic Status: Education, Class and Genetics. In N. Smelser and P. Baltes Eds., International Encyclopedia of the Social and Behavioral Sciences (pp. 41324141). Oxford: Elsevier.

Bowles S. and H. Gintis (2002). The inheritance of inequality. Journal of Economic Perspectives, 16, 3-30.

Brunello G. and D. Checchi (2005). School quality and family background in Italy. Economics of Education Review, 24, 563-577.

Card D. (1999). The causal effect of education on earnings. In Ashenfelter and Card Eds., Handbook of Labor Economics (pp. 1801-1863). Elsevier, North Holland.

Checchi, D., Fiorio C. and M. Leonardi (2008). Intergenerational persistence in educational attainment in Italy. IZA Discussion paper no. 3622.

Chusseau N. and J. Hellier (2012). Education, intergenerational mobility and inequality. In J. Hellier and N. Chusseau Eds, Growing Income Inequalities, Economic Analyses (pp. 227-273). Palgrave Macmillan.

Cohn E. and J.T. Addison (1994). The economic returns of lifelong learning. WP B-97-04, University of South Carolina, College of Business Administration.

Corak M. (2006). Do poor children become poor adults? Lessons from a cross country comparison of generational earnings mobility. In J. Creedy and G. Kalb eds., Research on Economic Inequality, Vol. XIII (Amsterdam), 143-188.

Couch K.A. and T.A. Dunn (1997). Intergenerational Correlations in Labor Market Status: A Comparison of The United States and Germany. Journal of Human Resources, 32(1), 210-232.

Dearden L., Machin S. and Reed H. (1997). Intergenerational Mobility in Britain. Economic Journal, 107(440), 47-66.

Entwistle D. and K. Alexander (1992). Summer setback: race, poverty, school composition and educational stratification in the United States. American Sociological Review, 57, 72-84.

Ermisch J. and M. Francesconi (2001). Family Matters: Impacts of Family Background on Educational Attainments. Economica, 68, 137-156. 
Fabre A. and S. Moullet (2004). Externalités de l'éducation et mobilité intergénérationnelle : application au cas français. Economie et Prévision, 5(166), 19-37.

Goux D. and E. Maurin (1994). Education, expérience et salaire : tendance récente et évolution de long-terme. Economie et Prévision, $\mathrm{n}^{\circ} 116,155-178$.

Goux D. and E. Maurin (1996). La mobilité sociale en France. In Données sociales 1996, Paris, INSEE, 13-26.

Gronau R. (1974). Wage Comparisons: A Selectivity Bias. Journal of Political Economy, 82, 1119-1143.

Grawe N.D. (2004). Reconsidering the use of nonlinearities in intergenerational earnings mobility as a test for credit constraints. Journal of Human Resources, 39, 813-827.

Grawe N.D. and C. Mulligan (2002). Economic interpretations of intergenerational correlations. Journal of Economic Perspectives., 6, 45-58.

Han S. and C. Mulligan (2001). Human capital, heterogeneity, and estimated degrees of intergenerational mobility. Economic Journal, 111, 207-243.

Hanchane S. and S. Moullet (2000). Les rendements éducatifs privés : fondements, bilan et évaluations de nouvelles alternatives. Economie publique, 1(5), 23-87.

Heckman J.J. (1976). The Common Structure of Statistical Models of Truncation, Sample Selection, and Limited Dependent Variables, and a Simple Estimator for such Models. Annals of Economical and Social Measurement, 5, 475-492.

Heckman J.J. (1979). Sample Selection Bias as a Specification Error. Econometrica, 47, 153-161.

Jäntti M., Bratsberg B., Røed K., Oddbjørn R., Naylor R., Österbacka E., Björklund A. and T. Eriksson (2006). American exceptionalism in a new light: A comparison of intergenerational earnings mobility in the Nordic countries, the United Kingdom and the United States. IZA Discussion paper no. 1938.

Jarousse J.P. and A. Mingat (1986). Un réexamen du modèle de gains de Mincer. Revue Economique, 37(6).

Lauer C. (2003). Family background, cohort and education: A French-German comparison based on a multivariate ordered probit model of educational attainment. Labour Economics, 10, 231-251.

Lefranc A. and A. Trannoy (2005). Intergenerational earnings mobility in France: Is France more mobile than the US?, Annales d'Economie et de Statistique, 78, 57-77.

Lewis H.G. (1974). Comments on Selectivity Biases in Wage Comparisons. Journal of Political Economy, 82, 1145-1155.

Liu, J-T, S-Y. Chou and J-L. Liu (2006). Assymetreis in progression in higher education in Taiwan: Parental education and income effects. Economics of Education Review, 25, 647-658.

Liu, J-T, J.K. Hammit and C.J. Lin (2000). Family background and return to schooling in Taiwan. Economics of Education Review, 19, 113-125.

Mazumder B. (2005). Fortunate sons: New estimates of intergenerational mobility in the U.S. using social security earnings data. Review of Economics and Statistics, 87, 235-255.

Miller P., C. Mulvey, and N. Martin (1995). What do Twin Studies Reveal About the Economic Returns to Education: a Comparison of Australian and U.S. Findings. American Economic Review, 85(3), 586-599.

Mincer J. (1974). Schooling, Experience and Earnings. New York : Colombia University Press.

Mulligan C.B. (1997). Parental priorities and economic inequality. Chicago: University of Chicago Press.

Nicoletti C. and J. Ermisch (2007). Intergenerational earnings mobility: Changes across cohorts in Britain. The B.E. Journal of Economic Analysis and Policy, 7, Article 9.

Österberg T. (2000). Intergenerational income mobility in Sweden: What do tax data show?. Review of Income and Wealth, 46, 421-36.

Piketty T. (2000), Theories of Persistent Inequality and Intergenerational Mobility. In A. Atkinson and F. Bourguignon Eds., Handbook of income distribution (pp. 429-473). Vol.1 Chapter 8, Elsevier, North Holland..

Psacharopoulos G. (1985). Returns to education: a further international update and implications. Journal of Human Resources, 20, 583-604.

Psacharopoulos G. (1994). Returns to investment in education: a global update. World Development, 22, 13251343.

Psacharopoulos G. and Patrinos H. (2004). Returns to investment in education: a further update. Educational Economics. 12(2), 111-134.

Rouse C.E. (1999). Further estimates of the economic return to schooling from a new sample of twins, Economics of Education Review. 18(2), 149-157.

Solon G. (1992), Intergenerational income mobility in the United States, American Economic Review, 82, 393408.

Solon G. (2002), Cross-country Differences in intergenerational earnings mobility, Journal of Economic Perspectives, 16, 59-66.

Solon G. (2004), A model of intergenerational mobility variation over time and place, in: Miles Corak, ed., Generational income mobility in North America and Europe (Cambridge U. P.: Cambridge), 38-47.

Wössmann L. (2003), Specifying human capital. Journal of Economic Surveys, 17(3), 239-270. 


\section{Appendix 1: the optimal human capital}

$$
\begin{aligned}
& u_{i}=\left(W H_{i}\right)^{\alpha}-\delta E_{i}^{\beta}=\left(W H_{i}\right)^{\alpha}-\delta A^{-\beta / \gamma_{0}}\left(G\left(H_{i}\right)\right)^{-\beta \gamma_{3} / \gamma_{0}} H_{i,-1}{ }^{-\beta \gamma_{1} / \gamma_{0}} R_{i,-1}{ }^{-\beta \gamma_{2} / \gamma_{0}} H_{i}{ }^{\beta / \gamma_{0}} \\
& \frac{\partial u_{i}}{\partial H_{i}}=\alpha W^{\alpha} H_{i}^{\alpha-1}-\delta \frac{\beta}{\gamma_{0}} A^{-\beta / \gamma_{0}} H_{i,-1}{ }^{-\beta \frac{\gamma_{1}}{\gamma_{0}}} R_{i,-1}{ }^{-\beta \frac{\gamma_{2}}{\gamma_{0}}}\left(G\left(H_{i}\right)\right)^{-\beta \frac{\gamma_{3}}{\gamma_{0}}} H_{i}^{\frac{\beta}{\gamma_{0}}-1} \\
& +\delta \frac{\beta \gamma_{3}}{\gamma_{0}} A^{-\beta / \gamma_{0}} H_{i,-1}{ }^{-\beta \frac{\gamma_{1}}{\gamma_{0}}} R_{i,-1}{ }^{-\frac{\gamma_{2}}{\gamma_{0}}}\left(G\left(H_{i}\right)\right)^{-\frac{\beta \gamma_{3}}{\gamma_{0}}-1} G_{H_{i}}^{\prime} H_{i}^{\frac{\beta}{\gamma_{0}}}=0
\end{aligned}
$$

Multiplying this expression by $\frac{\gamma_{0}}{\beta \delta} A^{\beta / \gamma_{0}} H_{i} H_{i,-1}^{\beta \gamma_{1} / \gamma_{0}} R_{i,-1}^{\beta \gamma_{2} / \gamma_{0}}$ yields:

$\frac{\alpha \gamma_{0}}{\beta \delta} A^{\beta / \gamma_{0}} W^{\alpha} H_{i}^{\alpha} H_{i,-1}{ }^{\beta \frac{\gamma_{1}}{\gamma_{0}}} R_{i,-1}{ }^{\beta \frac{\gamma_{2}}{\gamma_{0}}}-\left(G\left(H_{i}\right)\right)^{-\beta \frac{\gamma_{3}}{\gamma_{0}}} H_{i}^{\frac{\beta}{\gamma_{0}}}\left(1+\gamma_{3} \varepsilon_{G / H}\right)=0$, with $\varepsilon_{G / H}=\frac{\partial G / G}{\partial H / H}$

And finally: $H_{i}=C W^{\frac{\alpha \gamma_{0}}{\beta-\alpha \gamma_{0}}} H_{i,-1} \frac{\beta \gamma_{1}}{\beta-\alpha \gamma_{0}} R_{i,-1} \frac{\beta \gamma_{2}}{\beta-\alpha \gamma_{0}} G\left(H_{i}\right)^{\frac{\beta \gamma_{3}}{\beta-\alpha \gamma_{0}}}$, with $C=\left(\frac{\alpha \gamma_{0} A^{\beta / \gamma_{0}}}{\beta \delta\left(1+\gamma_{3} \varepsilon_{G / H}\right)}\right)^{\frac{\gamma_{0}}{\beta-\alpha \gamma_{0}}}$.

\section{Appendix 2.}

Table A2. Average wage for skill levels and for each professional occupation

\begin{tabular}{|l|c|c|}
\hline \multicolumn{1}{|c|}{$\begin{array}{c}\text { Skill level } \\
\text { (10 levels) }\end{array}$} & \multicolumn{2}{c|}{$\begin{array}{c}\text { Average wage } \\
\text { for skill levels }\end{array}$} \\
\hline & $\mathbf{1 9 7 9}$ & $\mathbf{1 9 8 5}$ \\
\hline 1. Primary education not completed & 2160 & 5031 \\
\hline 2. Primary education completed & 3313 & 7439 \\
\hline 3. Secondary education (1st cycle) & 3646 & 7802 \\
\hline 4. Secondary education (2 ${ }^{\text {nd }}$ cycle) & 4530 & 9404 \\
\hline 5. Baccalaureate & 4655 & 9497 \\
\hline 6. University (1st cycle) & 4728 & 9534 \\
\hline 7. Medical and social degree & 3034 & 7179 \\
\hline 8. Vocational tertiary (BTS, DUT) & 3953 & 8792 \\
\hline 9. University (cycles 2 or 3) & 5222 & 10657 \\
\hline 10. Grandes écoles & 7574 & 15550 \\
\hline
\end{tabular}

\begin{tabular}{|l|c|c|}
\hline \multicolumn{1}{|c|}{$\begin{array}{c}\text { Professional occupations } \\
\text { (6 categories) }\end{array}$} & \multicolumn{2}{c|}{$\begin{array}{c}\text { Average wage for each } \\
\text { professional occupation }\end{array}$} \\
\hline & $\mathbf{1 9 7 9}$ & $\mathbf{1 9 8 5}$ \\
\hline 1. Farmers & 1906 & 6158 \\
\hline 2. Artisans & 4071 & 11587 \\
\hline 3. Executives & 5977 & 12794 \\
\hline 4. Intermediate occupations & 3476 & 7644 \\
\hline 5. Employees & 2320 & 5274 \\
\hline 6. Workers & 2206 & 5027 \\
\hline
\end{tabular}

\section{Appendix 3.}

Berthoin law has increased the age of compulsory schooling from 14 to 16 y.o. for the generations that have entered primary school since 1958, i.e., for generations born after 1952.

Table A3.Number of years spent in each cycle

\begin{tabular}{|l|c|c|}
\hline \multirow{2}{*}{\multicolumn{1}{|c|}{ Type of study }} & \multicolumn{2}{c|}{ Number of years spent in each type of study } \\
\cline { 2 - 3 } & $\begin{array}{c}\text { Before Berthoin law } \\
\text { (Entry in primary education before 1958) }\end{array}$ & $\begin{array}{c}\text { After Berthoin law } \\
\text { (Entry in primary education after 1958) }\end{array}$ \\
\hline Primary education not completed & $\mathbf{8}$ & $\mathbf{1 0}$ \\
\hline Primary education completed & $6+2=\mathbf{8}$ & $6+4=\mathbf{1 0}$ \\
\hline Secondary education 1st cycle & $6+5=\mathbf{1 1}$ \\
\hline Baccalaureate \& Secondary education 2 & nd cycle & \multicolumn{2}{|c|}{5 (primary) +8 (secondary) $=\mathbf{1 3}$} \\
\hline University (1st cycle) & 5 (primary) +7 (secondary) +2 (tertiary education) $=\mathbf{1 4}$ \\
\hline University 2 ${ }^{\text {nd }}$ cycle & 5 (primary) +7 (secondary) +4 (tertiary education) $=\mathbf{1 6}$ \\
\hline University 3rd cycle & 5 (primary) +7 (secondary) +6 (tertiary education) $=\mathbf{1 8}$ \\
\hline
\end{tabular}




\section{Appendix 4. Estimation of the wage equation}

Table A1.Wage equation with correction of the selection bias (Heckman Selection Model)

\begin{tabular}{|c|c|c|c|c|c|c|c|c|}
\hline \multirow[b]{2}{*}{ OUTCOME EQUATION: } & \multicolumn{2}{|c|}{1977} & \multicolumn{2}{|c|}{1985} & \multicolumn{2}{|c|}{1993} & \multicolumn{2}{|c|}{2003} \\
\hline & Coef & Std.Err & Coef & Std.Err & Coef & Std.Err & Coef & Std.Err \\
\hline Age & $0.013 * * *$ & $(0.0008)$ & $0.014 * * *$ & $(0.0009)$ & $0.012 * * *$ & $(0.001)$ & $0.018 * * *$ & $(0.001)$ \\
\hline \multicolumn{9}{|l|}{ Gender } \\
\hline Female & \multicolumn{2}{|c|}{ Ref } & \multicolumn{2}{|c|}{ Ref } & \multicolumn{2}{|c|}{ Ref } & \multicolumn{2}{|c|}{ Ref } \\
\hline Male & $0.256 * * *$ & $(0.005)$ & $0.169 * * *$ & $(0.006)$ & $0.230 * * *$ & $(0.011)$ & $0.118 * * *$ & $(0.015)$ \\
\hline \multicolumn{9}{|l|}{ Nationality } \\
\hline foreign & \multicolumn{2}{|c|}{ Ref } & \multicolumn{2}{|c|}{ Ref } & \multicolumn{2}{|c|}{ Ref } & & \\
\hline French & $0.159 * * *$ & $(0.010)$ & $0.164 * * *$ & $(0.011)$ & $0.143 * * *$ & $(0.020)$ & $0.090 * * *$ & $(0.029)$ \\
\hline French naturalized citizen & $0.134 * * *$ & $(0.017)$ & $0.130 * * *$ & $(0.018)$ & $0.100 * * *$ & $(0.032)$ & 0.028 & $(0.038)$ \\
\hline Marital status & & & & & & & & \\
\hline Single & & & $\mathrm{R}$ & & & & & \\
\hline Married & $0.090 * * *$ & $(0.006)$ & $0.065 * * *$ & $(0.006)$ & $0.068 * * *$ & $(0.010)$ & $0.057 * * *$ & $(0.016)$ \\
\hline Widowed & -0.025 & $(0.018)$ & 0.016 & $(0.022)$ & -0.005 & $(0.031)$ & -0.020 & $(0.056)$ \\
\hline Divorced & 0.008 & $(0.013)$ & -0.002 & $(0.012)$ & $0.070 * * *$ & $(0.017)$ & 0.004 & $(0.022)$ \\
\hline Experience & & & & & & & & \\
\hline Number of years at work & $0.026 * * *$ & $(0.001)$ & $0.021 * * *$ & $(0.001)$ & $0.021 * * *$ & $(0.002)$ & $0.014 * * *$ & $(0.002)$ \\
\hline Obsolescence & & & & & & & & \\
\hline (Number of years) $^{2}$ & $-0.0005 * * *$ & $(0.00001)$ & $-0.0004 * * *$ & $(0.00001)$ & $-0.0004 * * *$ & $(0.00003)$ & $-0.0004 * * *$ & $(0.00005)$ \\
\hline Size of the working district & & & & & & & & \\
\hline Paris agglomeration & & & $\mathrm{R}$ & & & & & \\
\hline Rural district & $-0.202 * * *$ & $(0.010)$ & $-0.108 * * *$ & $(0.011)$ & $-0.201 * * *$ & $(0.012)$ & $-0.069 * * *$ & $(0.022)$ \\
\hline$] 0-5000[$ inhabitants & $-0.182 * * *$ & $(0.013)$ & $-0.100 * * *$ & $(0.011)$ & $-0.192 * * *$ & $(0.021)$ & -0.010 & $(0.026)$ \\
\hline [5000-10000[ inhabitants & $-0.164 * * *$ & $(0.010)$ & $-0.119 * * *$ & $(0.012)$ & $-0.180 * * *$ & $(0.018)$ & -0.047 & $(0.034)$ \\
\hline [10000-20000[ inhabitants & $-0.165 * * *$ & $(0.011)$ & $-0.125 * * *$ & $(0.011)$ & $-0.180 * * *$ & $(0.017)$ & $-0.067 * *$ & $(0.028)$ \\
\hline [20000-50000[ inhabitants & $-0.159 * * *$ & $(0.010)$ & $-0.126 * * *$ & $(0.012)$ & $-0.198 * * *$ & $(0.017)$ & $-0.129 * * *$ & $(0.028)$ \\
\hline [50000-100000[ inhabitants & $-0.154 * * *$ & $(0.009)$ & $-0.140 * * *$ & $(0.010)$ & $-0.169 * * *$ & $(0.017)$ & $-0.144 * * *$ & $(0.028)$ \\
\hline [100000-200000[ inhabitants & $-0.140 * * *$ & $(0.009)$ & $-0.105 * * *$ & $(0.011)$ & $-0.200 * * *$ & $(0.017)$ & $-0.107 * * *$ & $(0.029)$ \\
\hline [200000-2000000[ inhabitants & $-0.129 * * *$ & $(0.007)$ & $-0.104 * * *$ & $(0.007)$ & $-0.154 * * *$ & $(0.012)$ & $-0.081 * * *$ & $(0.020)$ \\
\hline Skill level & & & & & & & & \\
\hline Primary educ. not completed (lowest skill) & & & $\mathrm{R}$ & & & & & \\
\hline Primary education completed & $0.136 * * *$ & $(0.006)$ & $0.100 * * *$ & $(0.007)$ & $0.043 * * *$ & $(0.014)$ & $0.071 * *$ & $(0.028)$ \\
\hline Secondary education 1 st cycle & $0.166 * * *$ & $(0.006)$ & $0.142 * * *$ & $(0.007)$ & $0.156 * * *$ & $(0.013)$ & $0.115 * * *$ & $(0.027)$ \\
\hline Secondary education cycle 2 & $0.167 * * *$ & $(0.012)$ & $0.132 * * *$ & $(0.014)$ & $0.074 * *$ & $(0.035)$ & $0.081 * *$ & $(0.034)$ \\
\hline Baccalaureate & $0.089 * * *$ & $(0.015)$ & $0.063 * * *$ & $(0.016)$ & $0.106 * * *$ & $(0.039)$ & $0.071 *$ & $(0.037)$ \\
\hline University 1 st cycle (2 years) & $0.058 * * *$ & $(0.013)$ & $0.045 * * *$ & $(0.013)$ & $0.052 * *$ & $(0.023)$ & $0.092 * *$ & $(0.044)$ \\
\hline Vocational tertiary (BTS, DUT) & $0.123 * * *$ & $(0.018)$ & $0.151 * * *$ & $(0.015)$ & $0.153 * * *$ & $(0.022)$ & $0.183 * * *$ & $(0.024)$ \\
\hline Medical and social degree below doctor & $0.047 * *$ & $(0.020)$ & $0.099 * * *$ & $(0.020)$ & $0.157 * * *$ & $(0.024)$ & $0.168 * * *$ & $(0.035)$ \\
\hline University cycles 2 or 3 & $0.241 * * *$ & $(0.017)$ & $0.268 * * *$ & $(0.015)$ & $0.288 * * *$ & $(0.026)$ & $0.262 * * *$ & $(0.044)$ \\
\hline Grandes écoles & $0.487 * * *$ & $(0.017)$ & $0.528 * * *$ & $(0.017)$ & $0.598 * * *$ & $(0.029)$ & $0.536 * * *$ & $(0.063)$ \\
\hline Working sector & & & & & & & & \\
\hline Non market services & & & $\mathrm{R}$ & & & & & \\
\hline Agriculture, forestry and fishing & $-0.153 * * *$ & $(0.025)$ & $-0.094 * * *$ & $(0.021)$ & $-0.078^{* *}$ & $(0.033)$ & $-0.170 * * *$ & $(0.035)$ \\
\hline Production and distribution of energy & $0.142 * * *$ & $(0.015)$ & $0.165 * * *$ & $(0.014)$ & $0.228 * * *$ & $(0.031)$ & $0.078 *$ & $(0.040)$ \\
\hline Food industry, basic consumables & $0.067 * * *$ & $(0.009)$ & $0.068 * * *$ & $(0.009)$ & $0.075 * * *$ & $(0.015)$ & $0.043^{*}$ & $(0.026)$ \\
\hline Manufacture of intermediate goods & $0.130 * * *$ & $(0.009)$ & $0.082 * * *$ & $(0.009)$ & $0.129 * * *$ & $(0.016)$ & 0.015 & $(0.020)$ \\
\hline Capital equipment industries & $0.119 * * *$ & $(0.008)$ & $0.085 * * *$ & $(0.008)$ & $0.120 * * *$ & $(0.015)$ & 0.037 & $(0.024)$ \\
\hline Dwelling, civil and agricultural engineering & $0.019 *$ & $(0.010)$ & $-0.031 * * *$ & $(0.010)$ & 0.021 & $(0.018)$ & $-0.057 * * *$ & $(0.021)$ \\
\hline Wholesale and retail trade & $0.081 * * *$ & $(0.010)$ & $0.047 * * *$ & $(0.010)$ & $0.084 * * *$ & $(0.016)$ & $-0.045^{* *}$ & $(0.019)$ \\
\hline Transport and telecommunications & $0.053 * * *$ & $(0.009)$ & $0.058^{* * * *}$ & $(0.008)$ & $0.111^{* * *}$ & $(0.018)$ & 0.026 & $(0.027)$ \\
\hline $\begin{array}{l}\text { Rental and leasing real estate loans, market } \\
\text { services }\end{array}$ & $0.078 * * *$ & $(0.009)$ & $0.048 * * *$ & $(0.008)$ & $0.068 * * *$ & $(0.013)$ & $-0.047 * * *$ & $(0.016)$ \\
\hline Insurance and financial institutions & $0.207 * * *$ & $(0.014)$ & $0.196^{* * * *}$ & $(0.013)$ & $0.224 * * *$ & $(0.023)$ & $0.157 * * *$ & $(0.030)$ \\
\hline On-the-job training kill level & & & & & & & & \\
\hline Primary education completed & $0.086^{* *}$ & $(0.034)$ & 0.054 & $(0.083)$ & $0.132 * * *$ & $(0.035)$ & $0.166^{* * *}$ & $(0.078)$ \\
\hline Secondary education 1 st cycle & $0.073 * * *$ & $(0.010)$ & $0.063 * * *$ & $(0.012)$ & $0.080 * * *$ & $(0.019)$ & 0.010 & $(0.018)$ \\
\hline Secondary education cycle 2 & $0.202 * * *$ & $(0.017)$ & $0.188 * * *$ & $(0.016)$ & $0.162 * * *$ & $(0.029)$ & $0.086 *$ & $(0.044)$ \\
\hline Baccalaureate & $0.090 * * *$ & $(0.021)$ & $0.071 * * *$ & $(0.023)$ & $0.260 * * *$ & $(0.077)$ & $0.128 * *$ & $(0.049)$ \\
\hline University 1 st cycle & $0.134 * * *$ & $(0.014)$ & $0.143 * * *$ & $(0.013)$ & $0.206^{* * * *}$ & $(0.020)$ & $0.081 * * *$ & $(0.030)$ \\
\hline University $2^{\text {nd }}$ cycle & $0.047 * *$ & $(0.018)$ & $0.244 * * *$ & $(0.027)$ & $0.270 * * *$ & $(0.054)$ & $0.119 * * *$ & $(0.033)$ \\
\hline University third cycle & $0.230 * * *$ & $(0.033)$ & $0.098 * * *$ & $(0.030)$ & $0.258 * * *$ & $(0.058)$ & $0.252 * * *$ & $(0.040)$ \\
\hline Constant & $6.609 * * *$ & $(0.022)$ & $7.540 * * *$ & $(0.024)$ & $7.813 * * *$ & $(0.045)$ & $6.314 * * *$ & $(0.059)$ \\
\hline
\end{tabular}




\begin{tabular}{|c|c|c|c|c|c|c|c|c|}
\hline $\begin{array}{l}\text { SELECTION EQUATION: PROB. OF BEING A } \\
\text { FULL-TIME WAGE EARNER }\end{array}$ & Coef & Std.Err & Coef & Std.Err & Coef & Std.Err & Coef & Std.Err \\
\hline Age & $-0.025 * * *$ & $(0.001)$ & $-0.026 * * *$ & $(0.002)$ & $-0.008^{*}$ & $(0.004)$ & $-0.025 * * *$ & $(0.002)$ \\
\hline \multicolumn{9}{|l|}{ Gender } \\
\hline Female & \multicolumn{2}{|c|}{ Ref } & \multicolumn{2}{|c|}{ Ref } & \multicolumn{2}{|c|}{ Ref } & \multicolumn{2}{|c|}{ Ref } \\
\hline Male & $0.343 * * *$ & $(0.017)$ & $0.390 * * *$ & $(0.016)$ & $0.217 * * *$ & $(0.034)$ & $0.645 * * *$ & $(0.023)$ \\
\hline \multicolumn{9}{|l|}{ Marital status } \\
\hline Single & \multicolumn{2}{|c|}{ Ref } & \multicolumn{2}{|c|}{ Ref } & \multicolumn{2}{|c|}{ Ref } & \multicolumn{2}{|c|}{ Ref } \\
\hline Married & $0.082 * * *$ & $(0.024)$ & $0.128 * * *$ & $(0.022)$ & $0.097 * *$ & $(0.041)$ & $-0.120 * * *$ & $(0.031)$ \\
\hline Widowed & $0.105 * *$ & $(0.049)$ & -0.011 & $(0.055)$ & -0.109 & $(0.115)$ & 0.037 & $(0.083)$ \\
\hline Divorced & $0.275 * * *$ & $(0.053)$ & $0.291 * * *$ & $(0.041)$ & $0.398 * * *$ & $(0.073)$ & $0.129 * * *$ & $(0.046)$ \\
\hline \multicolumn{9}{|l|}{ Experience } \\
\hline Number of years at work & $-0.004 * * *$ & $(0.001)$ & $0.003 * *$ & $(0.001)$ & $0.007 *$ & $(0.004)$ & $0.012 * * *$ & $(0.002)$ \\
\hline \multicolumn{9}{|l|}{ Size of the working district } \\
\hline Paris agglomeration & \multicolumn{2}{|c|}{ Ref } & \multicolumn{2}{|c|}{ Ref } & \multicolumn{2}{|c|}{ Ref } & \multicolumn{2}{|c|}{ Ref } \\
\hline Rural district & $-0.925^{* * *}$ & $(0.025)$ & $-0.774 * * *$ & $(0.025)$ & $-0.435 * * *$ & $(0.053)$ & $-0.524 * * *$ & $(0.036)$ \\
\hline$] 0-5000[$ inhabitants & $-0.567 * * *$ & $(0.047)$ & $-0.496 * * *$ & $(0.036)$ & $-0.392 * * *$ & $(0.083)$ & $-0.420 * * *$ & $(0.048)$ \\
\hline [5000-10000[ inhabitants & $-0.356 * * *$ & $(0.037)$ & $-0.361 * * *$ & $(0.040)$ & $-0.403 * * *$ & $(0.075)$ & $-0.377 * * *$ & $(0.058)$ \\
\hline [10000-20000[ inhabitants & $-0.323 * * *$ & $(0.039)$ & $-0.354 * * *$ & $(0.039)$ & $-0.386 * * *$ & $(0.077)$ & $-0.363^{* * *}$ & $(0.053)$ \\
\hline [20000-50000[ inhabitants & $-0.228 * * *$ & $(0.038)$ & $-0.346 * * *$ & $(0.037)$ & $-0.397 * * *$ & $(0.070)$ & $-0.131 * *$ & $(0.054)$ \\
\hline$[50000-100000[$ inhabitants & $-0.154 * * *$ & $(0.037)$ & $-0.210 * * *$ & $(0.037)$ & $-0.436 * * *$ & $(0.074)$ & $-0.248 * * *$ & $(0.051)$ \\
\hline [100000-200000[ inhabitants & $-0.130 * * *$ & $(0.036)$ & $-0.228 * * *$ & $(0.036)$ & $-0.531 * * *$ & $(0.070)$ & $-0.302 * * *$ & $(0.054)$ \\
\hline [200000-2000000[ inhabitants & $-0.139 * * *$ & $(0.028)$ & $-0.240 * * *$ & $(0.027)$ & $-0.352 * * *$ & $(0.054)$ & $-0.213 * * *$ & $(0.038)$ \\
\hline \multicolumn{9}{|l|}{ Instrument } \\
\hline Child in the household less than 6 years old & $-0.141 * * *$ & $(0.022)$ & $-0.070 * * *$ & $(0.019)$ & $-0.109 * * *$ & $(0.040)$ & $-0.066^{* *}$ & $(0.029)$ \\
\hline Constant & $1.879 * * *$ & $(0.052)$ & $1.548 * * *$ & $(0.055)$ & $0.928 * * *$ & $(0.116)$ & $1.398 * * *$ & $(0.095)$ \\
\hline Log pseudo-likelihood & \multicolumn{2}{|c|}{-25042.57} & \multicolumn{2}{|c|}{-24196.30} & \multicolumn{2}{|c|}{-7546.45} & \multicolumn{2}{|c|}{-18133.55} \\
\hline Atanh $\rho$ & $-0.141 * * *$ & $(0.042)$ & $-0.578 * * *$ & $(0.066)$ & $0.135 * * *$ & $(0.052)$ & $-0.791 * * *$ & $(0.060)$ \\
\hline $\operatorname{Ln} \sigma$ & $-1.045^{* * *}$ & $(0.011)$ & $-1.020 * * *$ & $(0.021)$ & $-1.019 * *$ & $(0.018)$ & $-0.457 * * *$ & $(0.028)$ \\
\hline Rho $(\rho)$ & \multicolumn{2}{|c|}{-0.140} & \multicolumn{2}{|c|}{-0.521} & \multicolumn{2}{|c|}{0.134} & \multicolumn{2}{|c|}{-0.659} \\
\hline Sigma $(\sigma)$ & \multicolumn{2}{|c|}{0.351} & \multicolumn{2}{|c|}{0.360} & \multicolumn{2}{|c|}{0.360} & \multicolumn{2}{|c|}{0.632} \\
\hline $\begin{array}{l}\text { Walt test of independent equations } \\
(\rho=0)\end{array}$ & $\chi^{2}=1$ & $0 * * *$ & $\chi^{2}=7$ & $6 * * *$ & $\chi^{2}=$ & & $\chi^{2}=16$ & $2 * * *$ \\
\hline Number of observations & 23 & & & & & & & \\
\hline
\end{tabular}

\section{Appendix 5. Calculation of the skill premia}

1) The skill premium in relation to the lowest skill (primary education not completed) is obtained by the exponential of the sum of the coefficients in the wage equation of all the successive stages of studies followed by the individual.

2) The marginal skill premium is calculated in relation to the skill level just before (e.g., in 1977 the marginal skill premium for the bac is $e^{0,089}=1.09$ ). Note that, for all tertiary education levels, the marginal skill premia are calculated in relation to the bac, except for the university $2^{\text {nd }} \& 3^{\text {rd }}$ cycles for which the reference is the University $1^{\text {st }}$ cycle.

3) The skill premium of each skill above the bac in relation to the bac is obtained by the ratio $\mathrm{SP}_{k} / \mathrm{SP} 1_{b a c}$ for all the courses of study $k$ higher than the bac. 